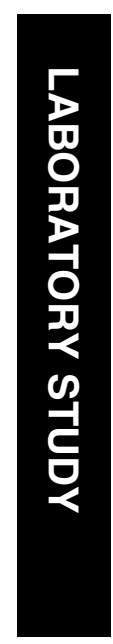

\title{
Expression of growth factors in the conjunctiva from patients with active trachoma
}

${ }^{1}$ Department of Ophthalmology, College of Medicine, King Saud University, Riyadh, Saudi Arabia

${ }^{2}$ Department of Ophthalmology, University of Leuven, Belgium

${ }^{3}$ Laboratory of Histochemistry and Cytochemistry, University of Leuven, Belgium

Correspondence: AM Abu El-Asrar,

Department of Ophthalmology, King Abdulaziz University Hospital, Airport Road, PO Box 245, Riyadh 11411, Saudi Arabia

Fax: $96614775724 /$ 4775741.

E-mail: abuasrar@

KSU.edu.sa

Received: 15 December 2004

Accepted in revised form: 22 February 2005 Published online: 8 April 2005

This work was supported in part by the College of Medicine Research Centre, King Saud University

\begin{abstract}
Purpose The blinding complications of trachoma are associated with progressive conjunctival fibrosis due to excessive accumulation of extracellular matrix (ECM) components. We studied the processes involved in the regulation of fibrosis in trachoma by investigating the expression of the fibrogenic and angiogenic connective tissue growth factor (CTGF) and basic fibroblast growth factor (bFGF), the angiogenic vascular endothelial growth factor (VEGF), the angiogenesis-associated endothelial cell marker CD105 (endoglin), and the ECM protein tenascin in the conjunctiva. Methods Conjunctival biopsy specimens from six patients with active trachoma, and six control subjects were studied by immunohistochemical techniques using monoclonal and polyclonal antibodies directed against CTGF, bFGF, VEGF, CD105, and tenascin.

Results In the normal conjunctiva, weak immunoreactivity for VEGF was observed in epithelial cells. There was no immunoreactivity for the other antibodies. In all trachoma specimens, immunoreactivity for CTGF and bFGF was localized in monocytes/macrophages, positive for the CD68 marker. Strong immunoreactivity for VEGF was observed in epithelial cells and on vascular endothelial cells. CD105 immunoreactivity was observed on vascular endothelial cells. Immunoreactivity for tenascin was noted in the upper substantia propria.

Conclusions These findings suggest that macrophages play an active role in conjunctival scarring, upregulated local production of CTGF, bFGF, and VEGF contributes to both fibrous tissue growth and angiogenesis, vascular endothelial cells are
\end{abstract}

AM Abu El-Asrar', SA Al-Kharashi', L Missotten² and $\mathrm{K}$ Geboes ${ }^{3}$ activated and are undergoing active angiogenesis, and deposition of tenascin reflect remodelling of the conjunctiva in trachomatous conjunctivitis.

Eye (2006) 20, 362-369. doi:10.1038/sj.eye.6701884; published online 8 April 2005

Keywords: trachoma; fibrosis; growth factors; angiogenesis; conjunctiva

\section{Introduction}

Trachoma is a chronic follicular keratoconjunctivitis caused by repeated reinfection with the ocular serovars $\mathrm{A}, \mathrm{B}, \mathrm{Ba}$, and $\mathrm{C}$ of Chlamydia trachomatis. It is the leading infectious cause of blindness worldwide, affecting an estimated 300-500 million people of whom 5.9 million are blind. The blinding complications of trachoma are associated with progressive conjunctival and subconjunctival scarring that may lead to dry eye syndrome, entropion, trichiasis, and corneal blindness. ${ }^{1}$ The pathological mechanisms involved in chronic progressive conjunctival scarring in trachoma that lead to blindness remain incompletely defined. However, in previous immunohistochemical studies we have demonstrated that the tissue damage might result from immunological mechanisms involving $\mathrm{T}$ lymphocytes, macrophages, gelatinase $\mathrm{B}$, and cytokines released by resident conjunctival cells, and by inflammatory cells infiltrating the tissue. ${ }^{2-4}$

Growth factors regulate many of the processes crucial for normal repair after tissue injury, including chemotactic migration of inflammatory cells and fibroblasts, mitosis of cells, neovascularization, and synthesis of extracellular matrix (ECM) components. ${ }^{5,6}$ However, prolonged production of these 
cytokines can lead to excessive matrix accumulation and chronic fibrosis, often resulting in loss of tissue structure and function. Among these growth factors, connective tissue growth factor (CTGF), basic fibroblast growth factor (bFGF), and vascular endothelial growth factor (VEGF, also known as vascular permeability factor) are of major importance in this process.

CTGF is a cysteine-rich secretory protein of $36-38 \mathrm{kDa}$, which is composed of 349 amino-acid residues, and its gene belongs to the $\mathrm{CCN}$ family. It functions as a downstream mediator of transforming growth factor- $\beta$ (TGF- $\beta$ ) action on connective tissue cells, stimulating cell proliferation and ECM synthesis. CTGF acts as a fibroblast chemoattractant and mitogen, and also stimulates ECM production, cell attachment, cell survival, and angiogenesis. ${ }^{6,7}$ bFGF is a potent mitogen for many cell types including fibroblasts and endothelial cells. It is a potent angiogenic factor and is involved in tissue remodelling and regeneration. ${ }^{8}$ VEGF is a specific mitogen for vascular endothelial cells and plays a central role in the process of angiogenesis, and increases vascular permeability. It acts on receptors such as Flt-1 and KDR, which are expressed selectively on endothelial cells. ${ }^{9}$

CD105 (endoglin) is a proliferation-associated protein abundantly expressed in angiogenic endothelial cells. It is expressed on the cell surface as a $180 \mathrm{kDa}$ transmembrane glycoprotein. CD105 is a receptor for TGF- $\beta 1$ and TGF- $\beta 3$ and modulates TGF- $\beta$ signalling by interacting with TGF- $\beta$ receptors I and/or II. The levels of CD105 protein, mRNA, and promoter activity are upregulated by hypoxia and by TGF- $\beta 1$ in vascular endothelial cells. ${ }^{10}$

Tenascin is a large oligomeric ECM glycoprotein that is abundantly expressed during embryogenesis especially at epithelial-mesenchymal junctions, and in developing brain tissue. During adulthood, tenascin expression is markedly decreased in normal tissues, but reappears during wound healing, tissue remodelling, and tumorigenesis. Tenascin is believed to play important roles in tissue development, wound healing, and repair, because it mediates several cellular activities including cell adhesion and antiadhesion, migration, proliferation, and differentiation. ${ }^{11}$

Understanding the control mechanisms involved in conjunctival scarring in trachoma should facilitate the development of new therapeutic strategies to control this aberrant wound healing. Therefore, using immunohistochemical methods we examined the expression of CTGF, bFGF, and VEGF, the proliferative endothelial cell marker CD105, and tenascin in the conjunctiva from patients with active trachoma and from normal individuals.

\section{Materials and methods}

\section{Study population}

Six patients with intense follicular trachomatous inflammation ${ }^{1}$ ranging in age from 5 to 17 years (mean age 7.7 years) were included in the study. Upper palpebral conjunctival biopsy specimen was obtained from each patient after informed consent. None of the patients was on topical therapy. In addition, six upper palpebral conjunctival biopsy specimens were obtained from patients of the same age group who underwent cataract extraction or strabismus surgery without obvious inflammation served as controls, in full compliance with the tenets of the Declaration of Helsinki.

The conjunctival biopsy specimens were immediately fixed for 2-3h in B5 fixative composed of: (A) $90 \mathrm{ml}$ distilled water, $6 \mathrm{~g}$ mercuric chloride, $2.074 \mathrm{~g}$ sodium acetate; and (B) 37\% formaldehyde solution, $\mathrm{pH} 5.7$. Since the reagents can react among each other, $9 \mathrm{ml}$ of $\mathrm{A}$ and $1 \mathrm{ml}$ of $\mathrm{B}$ were mixed immediately before use. The specimens were then embedded in paraffin.

\section{Immunohistochemical staining}

After deparaffinization, endogenous peroxidase was abolished with $2 \%$ hydrogen peroxide in methanol for $20 \mathrm{~min}$, and nonspecific background staining was blocked by incubating the sections for $5 \mathrm{~min}$ in normal swine serum. For CTGF, bFGF, CD105, and tenascin detection, antigen retrieval was performed by boiling the sections in $10 \mathrm{mM}$ Tris-EDTA buffer ( $\mathrm{pH}$ 9) for $30 \mathrm{~min}$. For CD68 (KP1) detection, the sections underwent trypsinization for $10 \mathrm{~min}$ at $37^{\circ} \mathrm{C}$ using a mixture of $0.1 \%$ trypsin (Sigma-Aldrich, Bornem, Belgium) and 0.1\% $\mathrm{CaCl}_{2}$ at $\mathrm{pH}$ 7.8. Subsequently, the sections were incubated with the monoclonal and polyclonal antibodies listed in Table 1. Optimum working concentration and incubation time for the antibodies were determined earlier in pilot experiments. For bFGF, CD105, and tenascin immunohistochemistry, the sections were incubated for $30 \mathrm{~min}$ with goat anti-rabbit or antimouse immunoglobulins conjugated to peroxidaselabeled dextran polymer (EnVision ${ }^{+}$; Dako, Carpinteria, CA, USA).

For CTGF, VEGF, and CD68 (KP1) immunohistochemistry, the sections were incubated for $30 \mathrm{~min}$ with the biotinylated secondary antibody and reacted with the avidin-biotinylated peroxidase complex (Dako). The reaction product was visualized by incubation for $10 \mathrm{~min}$ in $0.06 \% 3.3^{\prime}$-diaminobenzidine (Sigma) and $0.01 \%$ hydrogen peroxide resulting in brown immunoreactive sites. The slides were faintly counterstained with Harris hematoxylin. Finally, the 
Table 1 Monoclonal and polyclonal antibodies used in the study

\begin{tabular}{|c|c|c|c|c|}
\hline \multicolumn{2}{|c|}{ Primary antibody } & \multirow{2}{*}{$\begin{array}{c}\text { Dilution } \\
1: 20\end{array}$} & \multirow{2}{*}{$\frac{\text { Incubation time ( } \mathrm{min})}{120}$} & \multirow{2}{*}{$\begin{array}{l}\text { Source }^{\mathrm{a}} \\
\text { Santa Cruz Biotechnology, Inc. }\end{array}$} \\
\hline - & Anticonnective tissue growth factor (L-20) (pc) & & & \\
\hline - & Antivascular endothelial growth factor (A-20) (pc) & $1: 100$ & 30 & Santa Cruz Biotechnology, Inc. \\
\hline$\bullet$ & Antibasic fibroblast growth factor (147) (pc) & $1: 20$ & 30 & Santa Cruz Biotechnology, Inc. \\
\hline$\bullet$ & Anti-CD105 (Clone SN6h $\left.{ }^{1}\right)(\mathrm{mc})$ & $1: 20$ & 120 & Dako \\
\hline$\bullet$ & Anti-tenascin (Clone T2H5) (mc) & $1: 20$ & 120 & Neomarkers \\
\hline$\bullet$ & Anti-CD68 (Clone KP1) (mc) & $1: 50$ & 30 & Dako \\
\hline
\end{tabular}

a'Location of manufacturers: Santa Cruz Biotechnology, Inc., Santa Cruz, CA, USA; Dako, Glostrup, Denmark; Neomarkers, Westinghouse Dr., Fremont, CA, USA.

$\mathrm{pc}=$ polyclonal $; \mathrm{mc}=$ monoclonal .

Table 2 Summary of staining results

\begin{tabular}{|c|c|c|c|c|c|c|c|c|}
\hline & \multicolumn{4}{|c|}{ Control specimens $(\mathrm{n}=6)$} & \multicolumn{4}{|c|}{ Trachoma specimens $(\mathrm{n}=6)$} \\
\hline & Epithelium & $\begin{array}{c}\text { Vascular } \\
\text { endothelium }\end{array}$ & Macrophages & Stroma & Epithelium & $\begin{array}{c}\text { Vascular } \\
\text { endothelium }\end{array}$ & Macrophages & Stromo \\
\hline CTGF & - & - & - & - & - & - & ++ & - \\
\hline bFGF & - & - & - & - & - & - & ++ & - \\
\hline VEGF & + & - & - & - & +++ & ++ & - & - \\
\hline CD105 & - & - & - & - & - & ++ & - & - \\
\hline Tenascin & - & - & - & - & - & - & - & ++ \\
\hline
\end{tabular}

CTGF, connective tissue growth factor; bFGF, basic fibroblast growth factor; VEGF, vascular endothelial growth factor.

- , No staining; + , weak staining; ++ , intense staining; +++ , very intense staining.

sections were rinsed in distilled water and coverslipped with glycerol.

Omission or substitution of the primary antibody with an irrelevant antibody of the same species and staining with chromogen alone were used as negative controls. Sections from patients with colorectal carcinoma and breast cancer were used as positive controls. The sections from the control patients were obtained from patients treated at the University Hospital (University of Leuven, Belgium).

All sections were examined by two independent observers (AMA, KG) and the staining was graded on the basis of the presence or absence of immunoreactivity, intensity of immunoreactivity $(+$, weak staining; ++ , intense staining; +++ , very intense staining), and localization of immunoreactivity.

\section{Results}

The routine histology and immunohistochemical findings of these biopsy specimens were previously reported. ${ }^{2,4}$ Briefly, the inflammatory infiltrate in the epithelium consisted of large numbers of macrophages, $\mathrm{T}$ lymphocytes, polymorphonuclear leucocytes, and dendritic cells. The stromal inflammatory infiltrate was organized as lymphoid follicles and as a diffuse infiltrate. The lymphoid follicles consisted of B lymphocytes. In the follicular centre, large macrophages and few
T lymphocytes were observed. In the area between the follicles and the epithelium, as well as in areas of diffuse infiltrate, a mixed population of $\mathrm{T}$ lymphocytes, macrophages, dendritic cells, B lymphocytes, and polymorphonuclear leucocytes was observed. A band of plasma cells was situated directly underneath the epithelium in which $\operatorname{Ig} \mathrm{A}^{+}$cells were most prevalent. In addition, the superficial conjunctival epithelial cells infected with $C$. trachomatis expressed major histocompatibility complex class II antigens. Immunoreactivity for gelatinase B was localized in macrophages. In the centre of the lymphoid follicles, the macrophages with gelatinase B immunoreactivity were large and some were multinucleated giant cells.

A summary of the results is given Table 2. There was no staining in the negative control slides and when the chromogen alone was applied (Figure 1a). In normal conjunctiva, patchy weak intracytoplasmic perinuclear immunoreactivity for VEGF was observed in the epithelium. In addition, some epithelial cells showed perimembranous immunoreactivity for VEGF. There was no immunoreactivity for CTGF, bFGF, CD105, and tenascin.

In all trachoma specimens, cytoplasmic immunoreactivity for CTGF (Figure 1b) and bFGF (Figure 1c) was noted in large inflammatory mononuclear cells. These cells were located in the dense inflammatory infiltrate in the upper substantia propria in 


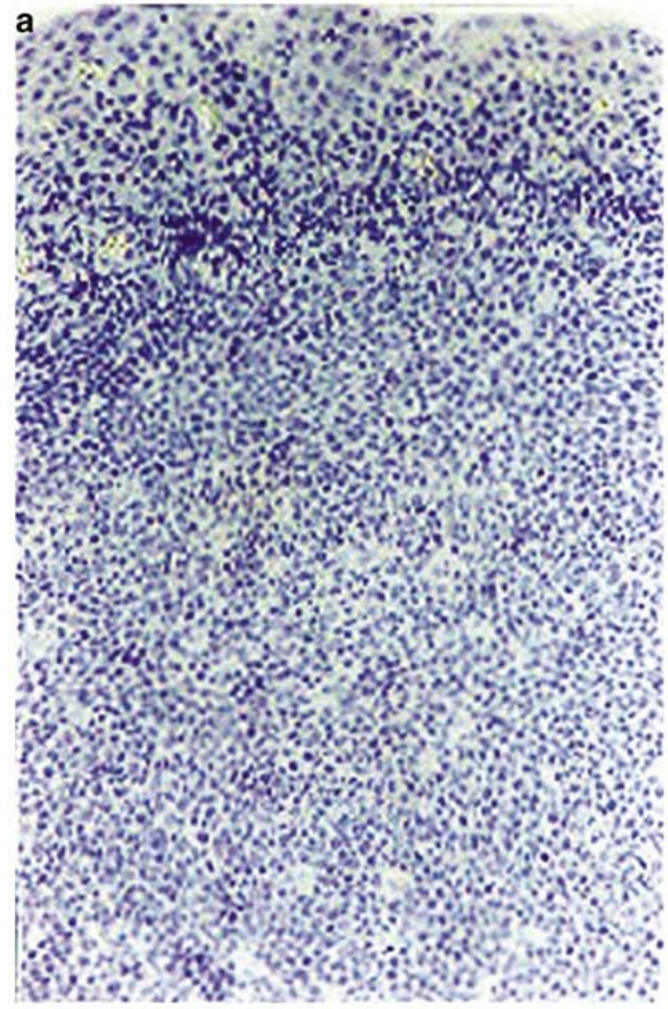

b

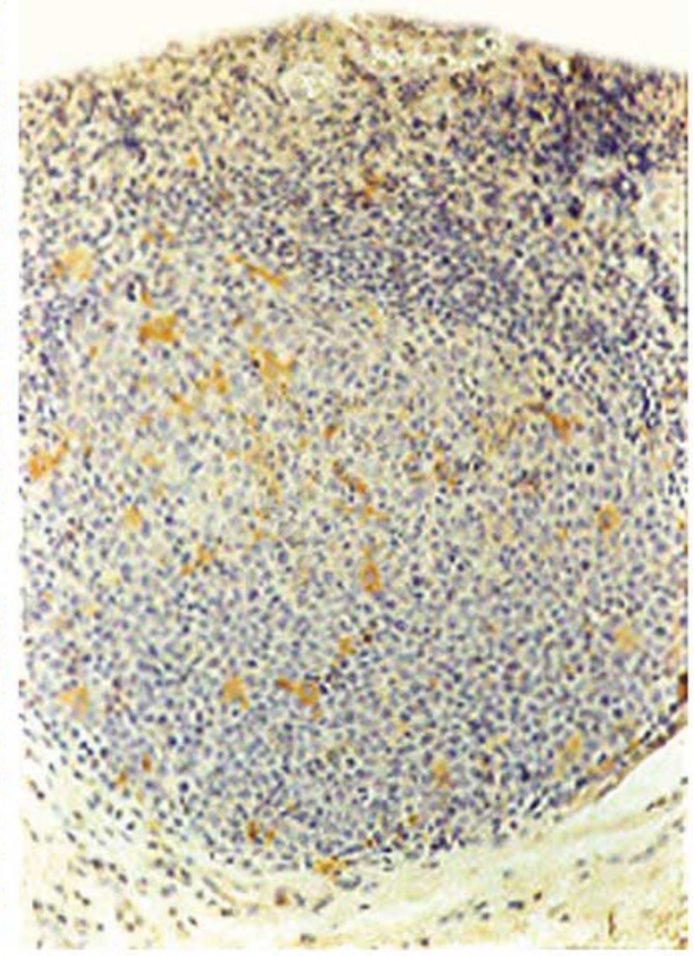

C

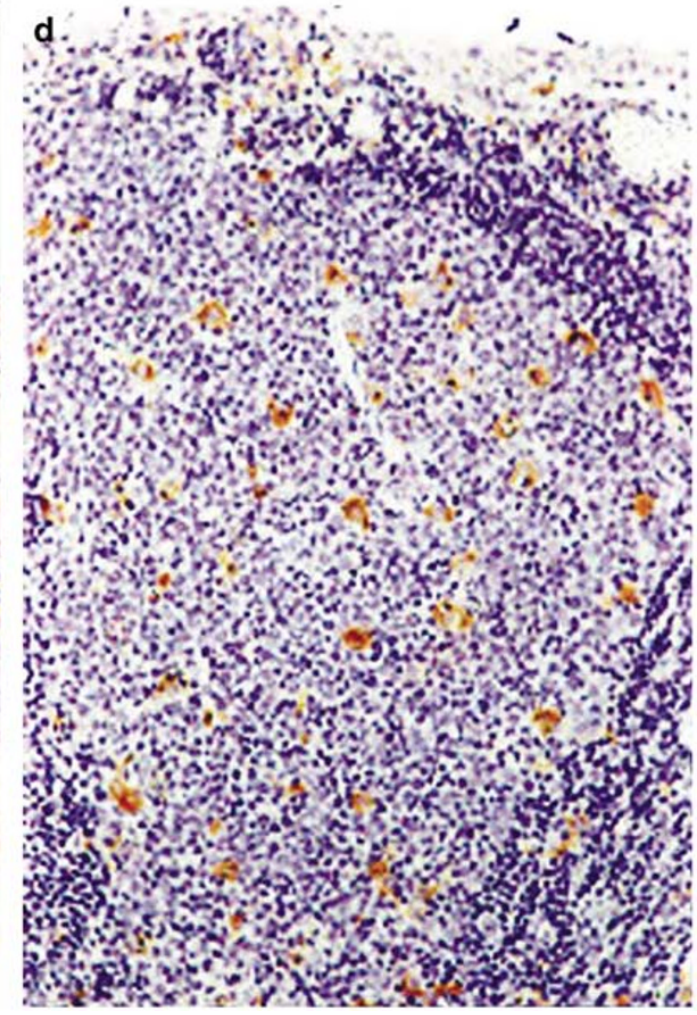

Figure 1 Immunohistochemical staining of trachomatous conjunctiva. (a) Negative control slide that was treated identically with the omission of the primary antibody showing no staining. (b) Staining for connective tissue growth factor showing immunoreactivity in inflammatory mononuclear cells. (c) Staining for basic fibroblast growth factor showing immunoreactivity in inflammatory mononuclear cells. (d) Staining for the monocyte/macrophage marker (CD68) (original magnification $\times 25$ ). 
the lymphoid follicles and in the diffuse infiltrate outside the follicles. In serial sections, the distribution of mononuclear cells expressing CTGF and bFGF was similar to the distribution of mononuclear cells that expressed the CD68 marker for monocytes/macrophages (Figure 1d). In the centre of the lymphoid follicles, the monocytes/macrophages with CTGF and bFGF immunoreactivity were larger and some were multinucleated giant cells. The morphology of these cells varied from round to dendritic. Upregulation of VEGF expression was noted in the epithelium.

Immunoreactivity for VEGF (Figure 2) and CD105 (Figure 3) was observed on vascular endothelial cells in the upper substantia propria in the area of dense inflammatory infiltrate. Band-like immunoreactivity for tenascin was noted in the upper substantia propria just underneath the epithelium. In addition,

immunoreactivity for tenascin was noted in the perivascular areas in the upper substantia propria (Figure 4). There was a close association between tenascin immunoreactivity and the inflammatory infiltrate.

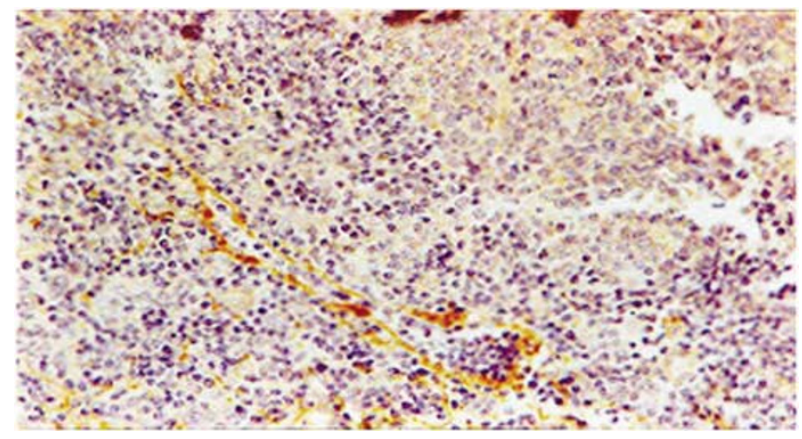

Figure 2 Trachoma. Immunohistochemical staining for vascular endothelial growth factor showing immunoreactivity on vascular endothelial cells (original magnification $\times 40$ ).

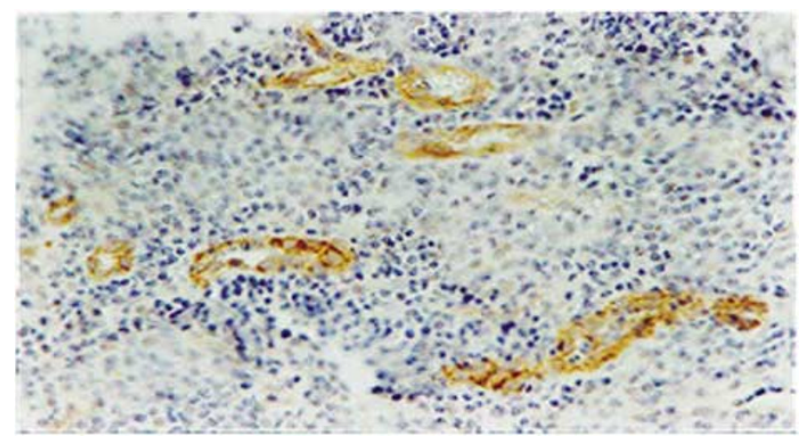

Figure 3 Trachoma. Immunohistochemical staining for CD105 showing immunoreactivity on vascular endothelial cells (original magnification $\times 40$ ).

\section{Discussion}

Macrophages play a central role in normal wound healing and in the pathogenesis of fibrotic disorders associated with chronic inflammatory states. After activation, macrophages produce many cytokines that chemoattract leucocytes and mesenchymal cells, such as fibroblasts, trigger the proliferation of fibroblasts, stimulate the production of ECM components, and modulate angiogenesis. Thus, macrophages are capable of influencing both fibrous tissue regrowth and capillary growth, and thus is a major regulator of the repair response. ${ }^{12}$ There is evidence that macrophages are activated during C. trachomatis infection. In previous immunohistochemical studies, we demonstrated the presence of increased numbers of activated macrophages in the conjunctival biopsy specimens from patients with active trachoma. $^{2,3}$ These macrophages showed cytoplasmic expression of the fibrogenic cytokines interleukin- $1 \alpha$, interleukin- $1 \beta$, tumor necrosis factor- $\alpha$, and platelet derived growth factor. ${ }^{3}$ In the normal conjunctiva, there was no immunoreactivity for CTGF and bFGF. In contrast, immunoreactivity for CTGF and

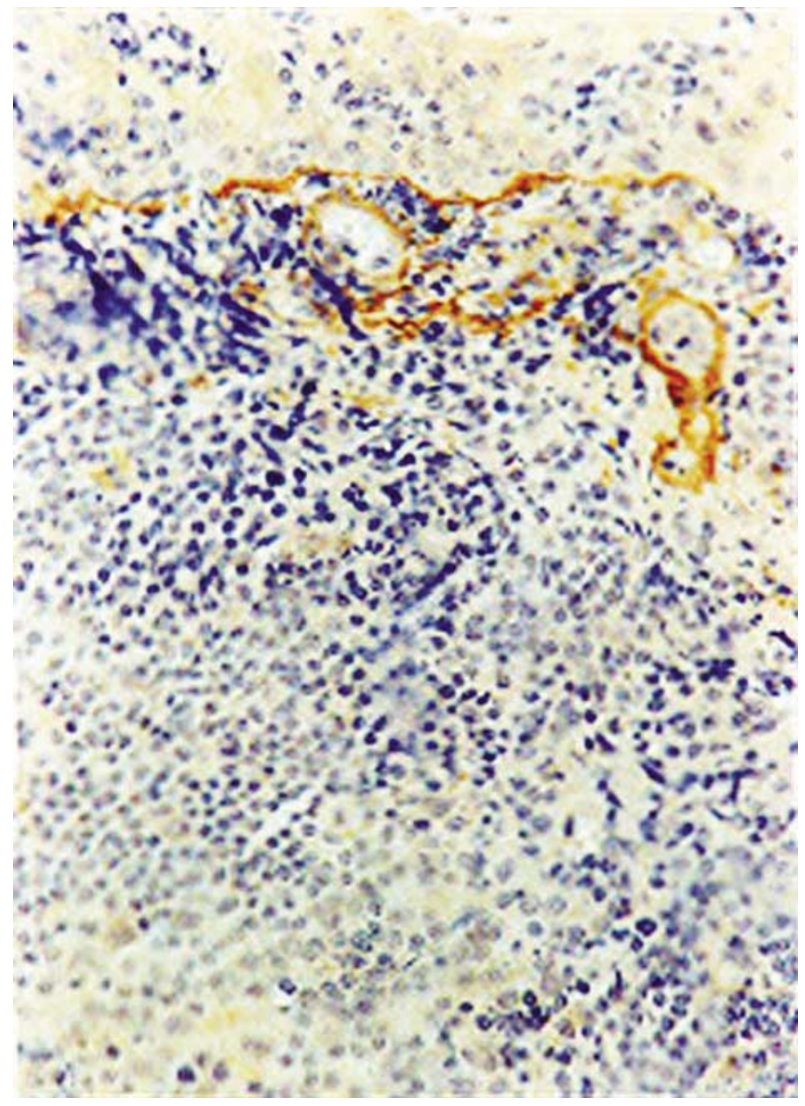

Figure 4 Trachoma. Immunohistochemical staining for tenascin showing immunoreactivity in the upper substantia propria and in the perivascular areas (original magnification $\times 40$ ). 
bFGF was detected in trachoma specimens and was specifically localized in macrophages, particularly in the lymphoid follicles. Similarly, CTGF ${ }^{5,13}$ and bFGF $^{14}$ were expressed in inflammatory mononuclear cells in other inflammatory and fibrotic disorders. CTGF has recently received much attention as a possible key determinant of progressive fibrosis and excessive scarring in several fibrotic diseases. ${ }^{713,15-19}$ In addition, an increased expression of CTGF was demonstrated in conjunctiva of patients with ocular cicatricial pemphigoid ${ }^{20}$ and in pterygium tissues ${ }^{21}$ suggesting that CTGF is one of the molecules involved in conjunctival fibrosis.

Metabolic alterations of ECM components and collagen metabolism occur in the conjunctival tissue from patients with trachoma. In previous studies, we demonstrated new type $\mathrm{V}$ collagen formation and increased types I, III, and IV collagen content in the conjunctiva from patients with active trachoma. ${ }^{22}$ Increased deposition of type IV collagen and new type V collagen formation was noted in scarred trachoma. ${ }^{23}$ In the present study, trachoma specimens showed a close association between the inflammatory infiltrate and tenascin immunoreactivity in the upper substantia propria and in the perivascular areas close to the epithelial cells. It has been suggested that tenascin acts as an immuno-modulator, ${ }^{24}$ promotes the transition of endothelial cells from a resting to a sprouting phenotype, ${ }^{25}$ and increases the expression of gelatinase $B$ by macrophages. ${ }^{26}$

Many studies indicate that CTGF can regulate the production of ECM components including types I, III, and IV collagen, fibronectin, fibromodulin, and tenascinc in several cells. ${ }^{27-29}$ Such findings are consistent with those indicating that subcutaneous injection of CTGF into NIH Swiss mice results in the formation of granulation tissue and fibrosis at the site of injection. ${ }^{27}$ Therefore, it is likely that CTGF may regulate the expression of ECM components in conjunctiva of patients with trachoma. Since CTGF is profibrotic, inhibition of this growth factor may be a new molecular target for therapeutic intervention in fibrotic diseases. It is conceivable that inhibition of CTGF might block the profibrotic effects of TGF- $\beta$, without affecting TGF- $\beta$ 's antiproliferative, antiinflammatory, and immunosuppressive effects. ${ }^{6,7}$

Angiogenesis is an important component of fibrous tissue growth, as it provides the essential nutrient support for cellular proliferation. ${ }^{12}$ In addition to producing cytokines that directly influence capillary endothelial cells, macrophages may modulate angiogenesis through the production of matrix metalloproteinases that effectively alter the ECM through degradation. ${ }^{12}$ In a previous study, we demonstrated increased activity of gelatinase B (matrix metalloproteinase-9) in conjunctival biopsy specimens from patients with active trachoma. Gelatinase B was localized in macrophages indicating that macrophages were primarily responsible for production of gelatinase B. ${ }^{4}$ Gelatinase B functions to promote angiogenesis by regulating endothelial cell attachment, proliferation, migration and tube formation. ${ }^{30,31}$ In addition, gelatinase $B$ cleaves denatured collagens (gelatins) and other matrix proteins $^{32}$ that may contribute to progressive breakdown of conjunctiva by degrading minor constituents of the ECM. Recently, there is strong evidence supporting a role for CTGF in the regulation of endothelial cell function and angiogenesis. CTGF can promote endothelial cell growth, migration, adhesion, and survival in vitro. CTGF is also active in vivo assays for angiogenic activity. ${ }^{33}$ In addition, CTGF contributes to the secretion of other angiogenic molecules such as gelatinase $\mathrm{B}^{34}$ and $\mathrm{bFGF}^{28}$ which are upregulated in the conjunctiva from patients with active trachoma. Therefore, it is likely that CTGF influences angiogenesis in trachoma through other indirect mechanisms by increasing the expression of gelatinase $\mathrm{B}$ and bFGF in macrophages. These findings suggest that CTGF, bFGF, and gelatinase $B$ produced by macrophages interact in mediating conjunctival angiogenesis and ECM remodelling in trachoma.

In the present study, we demonstrated that VEGF was constitutively expressed in conjunctival epithelial cells and was upregulated in trachoma. Our results are in agreement with previous studies that demonstrated constitutive cytoplasmic VEGF mRNA and protein expression in several epithelia, ${ }^{35}$ including the conjunctival epithelium. ${ }^{36}$ In addition, VEGF was expressed by vascular endothelium in the conjunctiva from patients with active trachoma. This finding is consistent with previous studies that demonstrated expression of VEGF mRNA and protein in stimulated human vascular endothelial cells. On the other hand, VEGF was not detected in endothelial cells under quiescent conditions. ${ }^{37}$ As endothelial cells are known to express the high-affinity VEGF receptors, these cells in trachoma appear to include the requisite elements for an autocrine pathway that may augment and/or amplify the paracrine effects of VEGF in stimulating angiogenesis and increasing vascular permeability and oedema. Similarly, in the pterygium tissue, an abnormal mass of fibrovascular tissue that extends from the conjunctiva onto the cornea, several reports described immunoreactivity for VEGF in the vascular endothelium. $^{21,36}$

In addition to VEGF, the vascular endothelium in trachoma expressed the proliferative endothelial marker CD105. The CD105 antibody binds preferentially to the activated endothelial cells that participate in angiogenesis, but expression is weak/or negative in vascular endothelium of normal tissues. Evidence that 
CD105 is involved in angiogenesis and vascular development, in maintaining vessel wall integrity, and in tumor progression has recently accumulated. ${ }^{10}$

Consistently, elevated levels of CD105 expression were detected on activated vascular endothelial cells in tissues undergoing active angiogenesis, such as wound healing, inflammation, and tumors. ${ }^{38,39}$ Moreover, the assessment of neovascularization by CD105 staining was found to represent a potential predictor of prognosis in different solid malignancies. ${ }^{39}$ Collectively, these data suggest that vascular endothelial cells in conjunctiva from patients with active trachoma are actively proliferating and are undergoing angiogenesis. These findings might explain vascular infiltration of the cornea (pannus) seen in patients with active trachoma.

\section{Acknowledgements}

We thank Ms Christel Van den Broeck for technical assistance, and Ms Connie B Unisa-Marfil for secretarial work.

\section{References}

1 Mabey DCW, Solomon AW, Foster A. Trachoma. Lancet 2003; 362: 223-229.

2 Abu El-Asrar AM, Van den Oord JJ, Geboes K, Missotten L, Emarah MH, Desmet V. Immunopathology of trachomatous conjunctivitis. Br J Ophthalmol 1989; 73: 276-282.

3 Abu El-Asrar AM, Geboes K, Tabbara KF, Al-Kharashi SA, Missotten L, Desmet V. Immunopathogenesis of conjunctival scarring in trachoma. Eye 1998; 12: 453-460.

4 Abu El-Asrar AM, Geboes K, Al-Kharashi SA, Al-Mosallam AA, Missotten L, Paemen L et al. Expression of gelatinase B in trachmatous conjunctivitis. $\mathrm{Br} J$ Ophthalmol 2000; 84: 85-91.

5 Esposito I, Bergmann F, Penzel R, di Mola FF, Shrikhande S, Büchler MW et al. Oligoclonal T-cell populations in an inflammatory pseudotumor of the pancreas possibly related to autoimmune pancreatitis: an immunohistochemical and molecular analysis. Virchows Arch 2004; 444: 119-126.

6 Blom IE, Goldschmeding R, Leask A. Gene regulation of connective tissue growth factor: new targets for antifibrotic therapy? Matrix Biol 2002; 21: 473-482.

7 Gupta S, Clarkson MR, Duggan J, Brady H. Connective tissue growth factor: potential role in glomerulosclerosis and tubulointerstitial fibrosis. Kidney Int 2000; 58: 1389-1399.

8 Okada-Ban M, Thiery JP, Jouanneau J. Fibroblast growth factor-2. Int J Biochem Cell Biol 2000; 32: 263-267.

9 Dvorak HF, Brown LF, Detmar M, Dvorak AM. Vascular permeability factor/vascular endothelial growth factor, microvascular hyperpermeability, and angiogenesis. Am J Pathol 1995; 146: 1029-1039.

10 Duff SE, Li C, Garland JM, Kumar S. CD105 is important for angiogenesis: evidence and potential applications. FASEB J 2003; 17: 984-992.

11 Jones FS, Jones PL. The tenascin family of ECM glycoproteins: structure, function, and regulation during embryonic development and tissue remodeling. Dev Dyn 2000; 218: 235-259.

12 Kovacs EJ, Di Pietro LA. Fibrogenic cytokines and connective tissue production. FASEB J 1994; 8: 854-861.

13 Tsuneyama K, Kouda W, Nakanuma Y. Portal and parenchymal alterations of the liver in idiopathic portal hypertension: a histological and immunochemical study. Pathol Res Pract 2002; 198: 597-603.

14 Hughes SE, Crossman D, Hall PA. Expression of basic and acidic fibroblast growth factors and their receptor in normal and atherosclerotic human arteries. Cardiovasc Res 1993; 27: 1214-1219.

15 Oemar BS, Werner A, Garnier JM, Do DD, Godoy N, Nauck $\mathrm{M}$ et al. Human connective tissue growth factor is expressed in advanced atherosclerotic lesions. Circulation 1997; 95: 831-839.

16 Allen JT, Knight RA, Bloor CA, Spiteri MA. Enhanced insulin-like growth factor binding protein-related protein 2 (connective tissue growth factor) expression in patients with idiopathic pulmonary fibrosis and pulmonary sarcoidosis. Am J Respir Cell Mol Biol 1999; 21: 693-700.

17 Igarashi A, Nashiro K, Kikuchi K, Sato S, Ihn H, Grotendorst GR et al. Significant correlation between connective tissue growth factor gene expression and skin sclerosis in tissue sections from patients with systemic sclerosis. J Invest Dermatol 1995; 105: 280-284.

18 Rachfal AW, Brigstock DR. Connective tissue growth factor (CTGF/CCN2) in hepatic fibrosis. Hepatol Res 2003; 26: 1-9.

19 Dammeier J, Brauchle M, Falk W, Grotendorst GR, Werner $\mathrm{S}$. Connective tissue growth factor: a novel regulator of mucosal repair and fibrosis in inflammatory bowel disease? Int J Biochem Cell Biol 1998; 30: 909-922.

20 Razzaque MS, Forster CS, Ahmed R. Role of connective tissue growth factor in the pathogenesis of conjunctival scarring in ocular cicatricial pemphigoid. Invest Ophthalmol Vis Sci 2003; 44: 1998-2003.

21 Van Setten G, Aspiotis M, Blalock TD, Grotendorst G, Schultz G. Connective tissue growth factor in pterygium: simultaneous presence with vascular endothelial growth factor-possible contributing factor to conjunctival scarring. Graefe's Arch Clin Exp Ophthalmol 2003; 241: 135-139.

22 Abu El-Asrar AM, Geboes K, Al-Kharashi SA, Tabbara KF, Missotten L. Collagen content and types in trachomatous conjunctivitis. Eye 1998; 12: 735-739.

23 Abu El-Asrar AM, Geboes K, Al-Kharashi SA, Al-Mosallam AA, Tabbara KF, Al-Rajhi AA et al. An immunohistochemical study of collagens in trachoma and vernal keratoconjunctivitis. Eye 1998; 12: 1001-1006.

24 Ruegg CR, Chiquet-Ehrismann R, Alkan SS. Tenascin, an extracellular matrix protein, exerts immunomodulatory activities. Proc Natl Acad Sci USA 1989; 86: 7437-7441.

25 Canfield AE, Schor AM. Evidence that tenascin and thrombospondin-1 modulate sprouting of endothelial cells. J Cell Sci 1995; 108: 797-809.

26 Khan KMF, Falcone DJ. Role of laminin induction of macrophage urokinase-type plasminogen activator and 92-KDa metalloproteinase expression. J Biol Chem 1997; 272: 8270-8275.

27 Frazier K, Williams S, Kothapalli D, Klapper H, Grotendorst GR. Stimulation of fibroblast cell growth, matrix production, and granulation tissue formation by connective tissue growth factor. J Invest Dermatol 1996; 107: 404-411. 
28 Wang JF, Olson ME, Ball DK, Brigstock DR, Hart DA Recombinant connective tissue growth factor modulates porcine skin fibroblast gene expression. Wound Rep Reg 2003; 11: 220-229.

29 Gore-Hyer E, Shegogue D, Markiewicz M, Lo S, Hazen-Martin D, Greene EL et al. TGF- $\beta$ and CTGF have overlapping and distinct fibrogenic effects on human renal cells. Am J Physiol Renal Physiol 2002; 283: F707-F716.

30 Jadhav U, Chigurupati S, Lakka SS, Mohanam S. Inhibition of matrix metalloproteinase- 9 reduces in vitro invasion and angiogenesis in human microvascular endothelial cells. Int $J$ Oncol 2004; 25: 1407-1414

31 Johnson C, Sung HJ, Lessner SM, Fini ME, Galis ZS. Matrix metalloproteinase- 9 is required for adequate angiogenic revascularization of ischemic tissues: potential role in capillary branching. Circ Res 2004; 94: 262-268.

32 Woessner JF. Matrix metalloproteinases and their inhibitors in connective tissue remodelling. FASEB J 1991; 5: 2145-2154.

33 Brigstock DR. Regulation of angiogenesis and endothelial cell function by connective tissue growth factor (CTGF) and cysteine-rich 61 (CYR61). Angiogenesis 2002; 5: 153-165.

34 Kondo S, Kubota S, Shimo T, Nishida T, Yosimichi G, Eguchi $\mathrm{T}$ et al. Connective tissue growth factor increased by hypoxia may initiate angiogenesis in collaboration with matrix metalloproteinases. Carcinogenesis 2002; 23 769-776.

35 Boussat S, Eddahibi S, Coste A, Fataccioli V, Gouge M, Housset $\mathrm{B}$ et al. Expression and regulation of vascular endothelial growth factor in human pulmonary epithelial cells. Am J Physiol Lung Cell Mol Physiol 2000; 279: L371-L378.

36 Jin J, Guan M, Sima J, Gao G, Zhang M, Liu Z et al. Decreased pigment epithelium-derived factor and increased vascular endothelial growth factor levels in pterygia. Cornea 2003; 22: 473-477.

37 Namiki A, Brogi E, Kearney M, Kim EA, Wu T, Couffinhal T et al. Hypoxia induces vascular endothelial growth factor in cultured human endothelial cells. J Biol Chem 1995; 270: 31189-31195.

38 Torsney E, Charton R, Parums D, Collis M, Arthur HM. Inducible expression of human endoglin during inflammation and wound healing in vivo. Inflamm Res 2002; 51: $464-470$.

39 Dales JP, Garcia S, Bonnier P, Duffaud F, Andrac-Meyer L, Ramuz O et al. CD105 expression is a marker of high metastatic risk and poor outcome in breast carcinomas. Correlation between immunohistochemical analysis and long-term follow-up in a series of 929 patients. Am J Clin Pathol 2003; 119: 374-380. 